\title{
Intergranular corrosion resistance of nanostructured austenitic stainless steel
}

\author{
A. T. Krawczynska $\cdot$ M. Gloc $\cdot$ K. Lublinska
}

Received: 8 November 2012/Accepted: 1 March 2013/Published online: 12 March 2013

(C) The Author(s) 2013. This article is published with open access at Springerlink.com

\begin{abstract}
Nanostructured metals and alloys possess very high strength but exhibit limited plasticity. Enhancement of the strength/ductility balance is of prime importance to achieve wide industrial applications. However, postdeformation heat treatment, which is usually used to improve plasticity, can lead to a decrease in other properties. In the case of austenitic stainless steels, heat treatment in the range from 480 to $815^{\circ} \mathrm{C}$ can increase their susceptibility to intergranular corrosion. The aim of the work reported in this paper was to determine if nanostructured austenitic stainless steel is susceptible to intergranular corrosion if heat treated for $1 \mathrm{~h}$ at $700{ }^{\circ} \mathrm{C}$. Samples of 316LVM austenitic stainless steel were hydrostatically extruded, in a multi-step process with the total true strain of 1.84 to produce a uniform microstructure consisting of nanotwins. These nanotwins averaged $21 \mathrm{~nm}$ in width and $197 \mathrm{~nm}$ in length. Subsequent annealing at $700{ }^{\circ} \mathrm{C}$ produced a recrystallised structure of 68-nm-diameter nanograins. The heat treatment improved the ductility from 7.8 to $9.2 \%$ while maintaining the ultimate tensile strength at the high level of $1485 \mathrm{MPa}$. Corrosion tests were performed in an aqueous solution consisting of $450 \mathrm{ml}$ concentrated $\mathrm{HNO}_{3}$ and $9 \mathrm{~g} \mathrm{NaF} / \mathrm{dm}^{3}$ (according to ASTM A262-77a). The evaluation of the corrosion resistance was based on transmission and scanning electron microscopic observation of the microstructure and chemical analyses. The results revealed that both the as-received and HE-processed samples are slightly susceptible to the intergranular corrosion after annealing at $700{ }^{\circ} \mathrm{C}$ for $1 \mathrm{~h}$.
\end{abstract}

\footnotetext{
A. T. Krawczynska $(\bowtie) \cdot$ M. Gloc $\cdot$ K. Lublinska Faculty of Materials Science and Engineering,

Warsaw University of Technology, Woloska 141, 02-507 Warsaw, Poland

e-mail: akrawczynska@wp.pl
}

\section{Introduction}

Nanostructured materials have attracted considerable attention because of their higher strength, hardness and wear resistance than the microstructural counterparts [1-4]. For example, precipitation-hardened nanostructured 2XXX aluminium alloy after severe plastic deformation (SPD) by hydrostatic extrusion (HE) possesses a strength similar to that of conventional 7XXX alloys, which are considered to be the strongest aluminium alloys [2]. Nanostructured 316LVM austenitic steel exhibits a lower friction coefficient under lubricated conditions than its microstructural counterpart [4] and showed less intensive wear damage. However, little is known about the other properties of nanometals, including their corrosion resistance. Recent research has shown that nanostructured 316 austenitic stainless steel is more resistant to pit nucleation than the conventional alloy [5]. It might be caused by the homogenization of the structure during HE. This favourable behaviour of nanostructured austenitic stainless steel raises a question about its resistance to intergranular corrosion. This form of corrosion is particularly perilous for stainless steel components operating in chemically aggressive environments at high temperature. The major cause of the susceptibility of austenitic steels to intergranular corrosion is the formation of chromium carbide, $\mathrm{Cr}_{23} \mathrm{C}_{6}$, at grain boundaries. This causes a depletion of chromium in the areas surrounding these carbides. This possibility of this form of corrosion must be taken into account when applying post-deformation heat treatment to enhance the ductility of nanometals [6-9], since the high strength is not accompanied by high ductility in the case of nanometals. Several methods have been proposed to avoid sensitising stainless steel, and thereby eliminating the risk of intergranular corrosion, including a reduction of the carbon 
content, the addition of elements like titanium or niobium and creating specially engineered grain boundaries [1012].

The aim of the reported work was to investigate whether improving the mechanical properties by SPD and subsequently annealing the nanostructured $316 \mathrm{LVM}$ austenitic stainless steel at $700{ }^{\circ} \mathrm{C}$ for $1 \mathrm{~h}$ affects its susceptibility to intergranular corrosion.

\section{Experimental}

Sandvik Bioline 316LVM austenitic stainless steel, supplied as cold-deformed 10-mm-diameter rods of the chemical composition given in Table 1, was employed.

Billets cut from the rods were subjected to a multi-pass HE process to achieve a final diameter of $4 \mathrm{~mm}$, which corresponds to a total true strain of 1.84. Samples of the asreceived and HE-processed material were annealed in air at $700{ }^{\circ} \mathrm{C}$ for $1 \mathrm{~h}$. Before corrosion tests the samples were ground and polished. Corrosion tests were performed in an aqueous solution consisting of $450 \mathrm{ml}$ concentrated $\mathrm{HNO}_{3}$ and $9 \mathrm{~g} \mathrm{NaF} / \mathrm{dm}^{3}$ (according to ASTM A262-77a). The evaluation of corrosion resistance was based on microstructural observations by transmission and scanning electron microscopes and chemical analyses.

Tensile testing was performed on the as-received, HEprocessed and annealed samples using a MTS Q Test/10 at a speed of $10^{-3} \mathrm{~m} / \mathrm{s}$. The dimensions of the tensile test samples are illustrated in Fig. 1.

Samples for the TEM examination were prepared by mechanical polishing to produce a disc of thickness of about $100 \mu \mathrm{m}$ and further thinning, to obtain electron transparency, was carried out by electropolishing. The microstructures were examined using a JEOL JEM 1200

Table 1 The chemical composition (wt $\%$ ) of 316LVM steel

\begin{tabular}{llllllllll}
\hline $\mathrm{C}$ & $\mathrm{Si}$ & $\mathrm{Mn}$ & $\mathrm{P}$ & $\mathrm{S}$ & $\mathrm{Cr}$ & $\mathrm{Ni}$ & $\mathrm{Mo}$ & $\mathrm{Cu}$ & $\mathrm{N}$ \\
\hline 0.025 & 0.6 & 1.7 & 0.025 & 0.003 & 17.5 & 13.5 & 2.8 & 0.1 & $<0.1$ \\
\hline
\end{tabular}

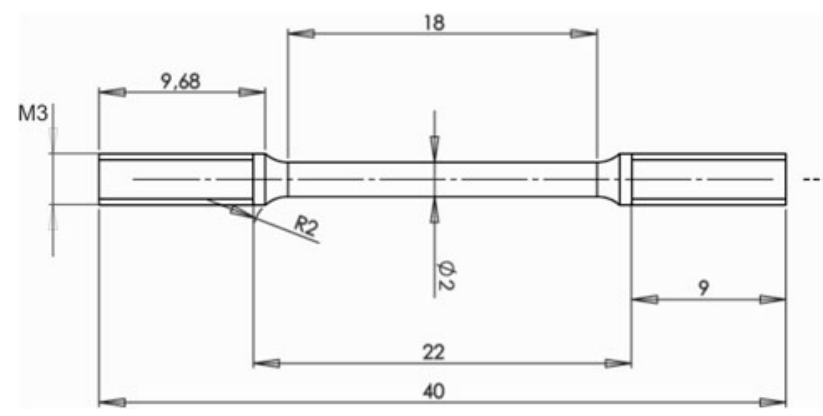

Fig. 1 Dimensions of samples for tensile tests
EX transmission electron microscope and a SEM 5500 scanning electron microscope. The microstructures were quantified on the basis of the images obtained. The images were analysed using computer-aided image analysis. Precipitates and etched dimples present in the samples after the various treatments were analysed in terms of their size, shape and chemical composition. The size of precipitates and etched dimples were characterised as the equivalent diameter, $d_{2}$, defined as the diameter of a circle of area equal to the surface area of the given precipitate or etched dimple. To quantify the variation in size a variation coefficient, CV $\left(d_{2}\right)$, defined as the ratio of the standard deviation to the mean value, was applied. The shape was described by the elongation parameter, which is the ratio of the maximum to the equivalent diameter $d_{\max } / d_{2}$. The phase analysis of selected carbides was undertaken by the nanodiffraction mode using a high-resolution scanning electron microscope HD2700.

\section{Results}

\section{Microstructural observations before annealing}

The microstructure of the as-received and HE-processed samples consisted of deformation twins and shear bands. The HE sample possessed significantly refined deformation twins with an average length of $197 \mathrm{~nm}$ and width of $21 \mathrm{~nm}$ with a high density of dislocations, details of which can be found elsewhere [13]. To achieve better characterisation of the microstructure features like twins, dark-field observations were performed, as illustrated in Fig. 2.

\section{Tensile tests}

The stress-strain curves of 316LVM austenitic stainless steel in the as-received state, HE-processed, and HE-processed and annealed at $700{ }^{\circ} \mathrm{C} / 1 \mathrm{~h}$ are shown in Fig. 3 and determined values are shown in Table 2.

It is evident that HE enhanced the strength. The yield stress was increased from 839 to $1504 \mathrm{MPa}$ and the ultimate tensile strength from 1024 to $1793 \mathrm{MPa}$. However, the uniform elongation dropped from 7.1 to $1.0 \%$ and total elongation from 24 to $7.8 \%$. After annealing the total elongation increased from 7.8 to $9.2 \%$ with only a slight loss of strength. This indicated that significant improvement in the strength-ductility balance can be achieved by low-temperature annealing. It is well-known that this heat treatment can increase the susceptibility of austenitic stainless steels to intergranular corrosion. For this reason, it is always necessary to perform microstructural observations to verify the presence of chromium carbides responsible for intergranular corrosion. 
(a)

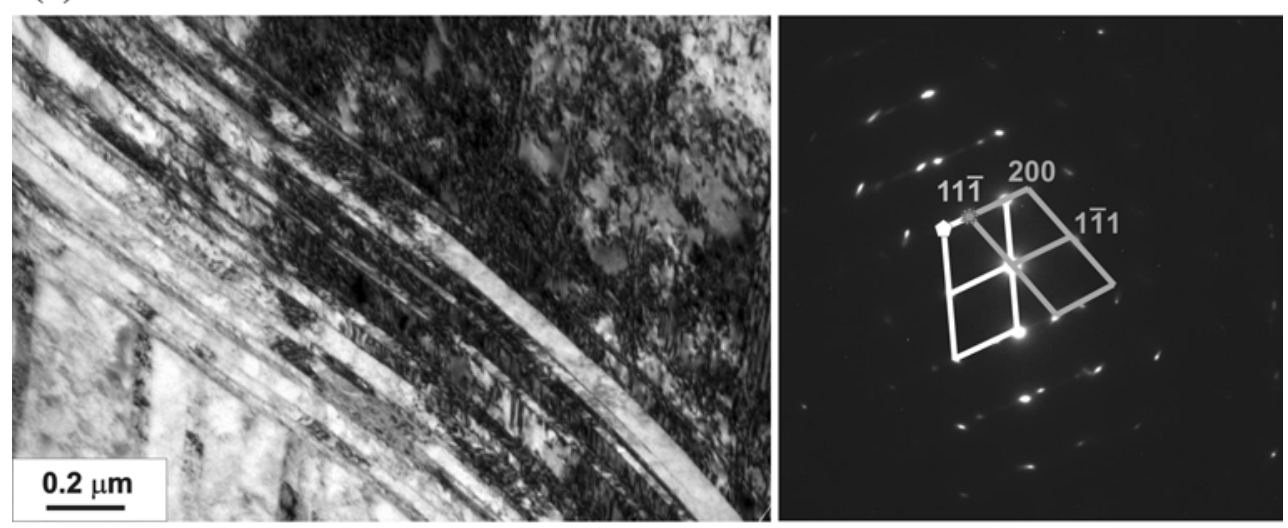

(b)

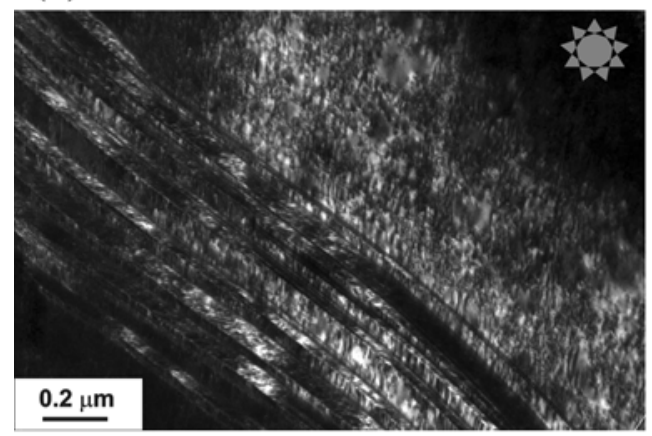

(c)

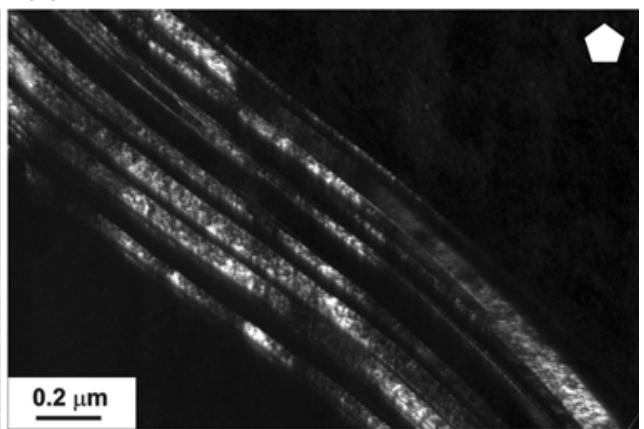

(d)

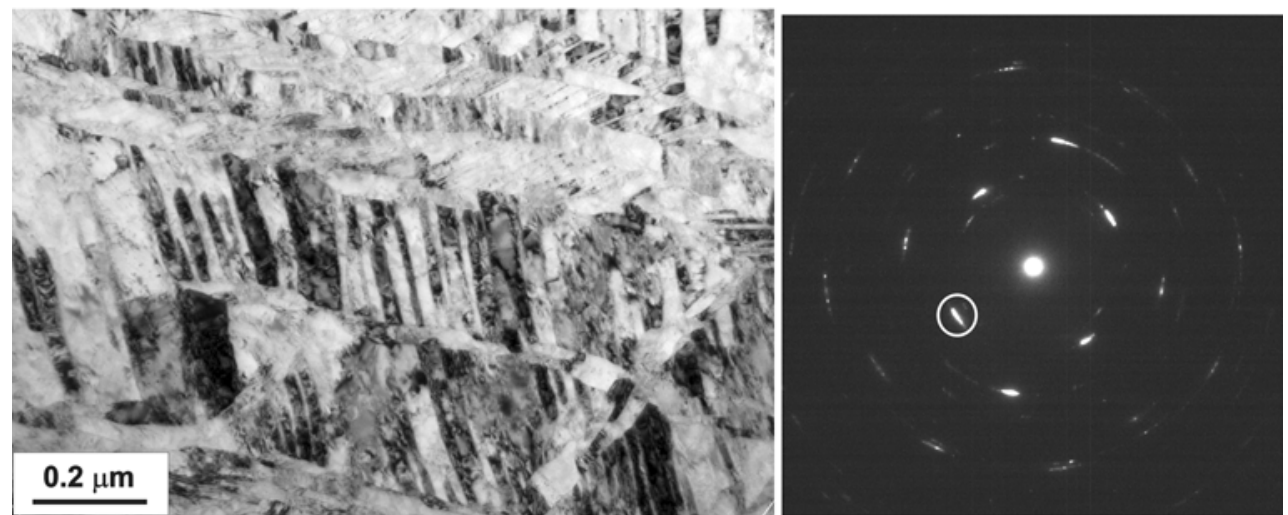

(e)

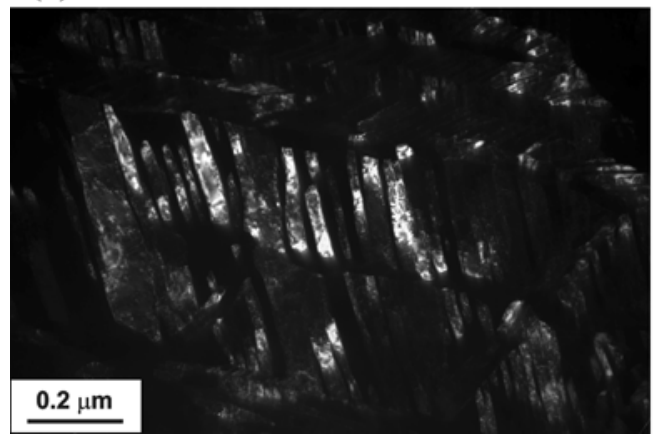

Fig. 2 a The microstructure of the as-received sample in the bright field with the diffraction pattern in the orientation [011] of the matrix and [0-1-1] of twins; $\mathbf{b}$, $\mathbf{c}$ microstructures in the dark field of the matrix and twins; $\mathbf{d}$ the microstructure of the HE-processed sample in the bright field and the corresponding diffraction pattern with the circled spot used in the dark field; e the microstructure of twins in the dark field 


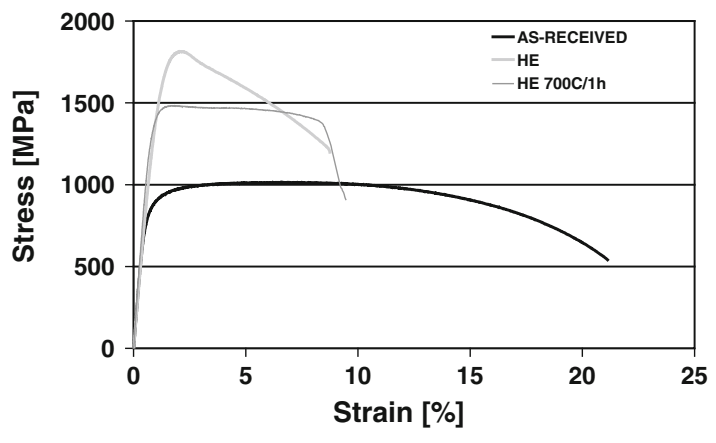

Fig. 3 Stress-strain curves of austenitic stainless steel in the as-received state, HE-processed, and HE-processed and annealed at $700{ }^{\circ} \mathrm{C} / 1 \mathrm{~h}$

\section{Microstructure after annealing at $700{ }^{\circ} \mathrm{C}$ for $1 \mathrm{~h}$}

The grain size and shape of the microstructures produced by annealing at $700{ }^{\circ} \mathrm{C}$ for $1 \mathrm{~h}$ have been described previously [13]. It should be noted that nanocarbides were evident in both the as-received and HE-processed samples, as shown in Fig. 4. The nanocarbides are formed at the intersections of shear bands and at the boundaries of the twins and grains. In the as-received samples carbides appear much more sparsely than in the HE-processed samples. Therefore, only their average equivalent diameter, $39 \pm 15 \mathrm{~nm}$, was determined, which is comparable to the average equivalent diameter of $33 \pm 12 \mathrm{~nm}$ of the carbides in the HE-processed samples. The carbides are elongated which is expressed in their parameter of elongation (1.40).
Furthermore, their coefficient of variation is only 0.36 , which suggests that they are relatively homogenous in size.

Chemical analyses of the carbides in the as-received and HE-processed samples after annealing at $700{ }^{\circ} \mathrm{C} / 1 \mathrm{~h}$ were undertaken. Results for a few chosen carbide particles are presented in Fig. 5 and Tables 3 and 4. The chemical analysis shows that precipitates rich in $\mathrm{Mo}$ and also $\mathrm{Cr}$ are present in the as-received and HE-processed samples. $\mathrm{Cr}$-rich precipitates are particularly hazardous as their formation reduces the chromium content in the area close to the grain boundaries which induces intergranular corrosion. The carbide particles in the grain boundaries are strongly cathodic to the adjoining chromium depleted zones. In the HE-processed sample, phase analysis was carried out and an example of the diffraction pattern obtained for a selected carbide particle is shown in Fig. 6. Examination of the pattern gave clear evidence of the presence of $\mathrm{Cr}_{23} \mathrm{C}_{6}$ carbide in the annealed structure.

\section{Corrosion behaviour of annealed samples}

Before commencing the corrosion tests the surface is totally free of dimples or scratches as indicated in Fig. 7a, b.The surfaces of samples after the corrosion tests, on which etched dimples are visible, are shown in Fig. 7c-f. The dimples were formed at the shear bands and at both grain and twin boundaries. These dimples could be the effect of corrosion of the areas surrounding the $\mathrm{Cr}$ - and Mo-rich precipitates resulting from the reduced chromium

Table 2 Mean values and standard deviation of ultimate tensile strength

\begin{tabular}{|c|c|c|c|c|c|c|c|c|}
\hline & \multicolumn{2}{|l|}{ YS } & \multicolumn{2}{|l|}{ UTS } & \multicolumn{2}{|l|}{$A_{\mathrm{u}}$} & \multicolumn{2}{|l|}{$A_{\mathrm{t}}$} \\
\hline & $\mathrm{E}(\mathrm{MPa})$ & $\mathrm{SD}(\mathrm{MPa})$ & $\mathrm{E}(\mathrm{MPa})$ & $\mathrm{SD}(\mathrm{MPa})$ & $\mathrm{E}(\%)$ & $\mathrm{SD}(\%)$ & $\mathrm{E}(\%)$ & $\mathrm{SD}(\%)$ \\
\hline As-received & 839 & 24 & 1024 & 12 & 7.1 & 0.8 & 24.0 & 2.2 \\
\hline $\mathrm{HE}$ & 1504 & 31 & 1793 & 21 & 1.0 & 0 & 7.8 & 0.1 \\
\hline $\mathrm{HE}+700{ }^{\circ} \mathrm{C} / 1 \mathrm{~h}$ & 1357 & 11 & 1485 & 8 & 1.0 & 0.3 & 9.2 & 3.6 \\
\hline
\end{tabular}

UTS; uniform elongation, $A_{\mathrm{u}}$ and total elongation, $A_{\mathrm{t}}$ in the as-received state, HE-processed, and HE-processed and annealed at $700{ }^{\circ} \mathrm{C} / 1 \mathrm{~h}$
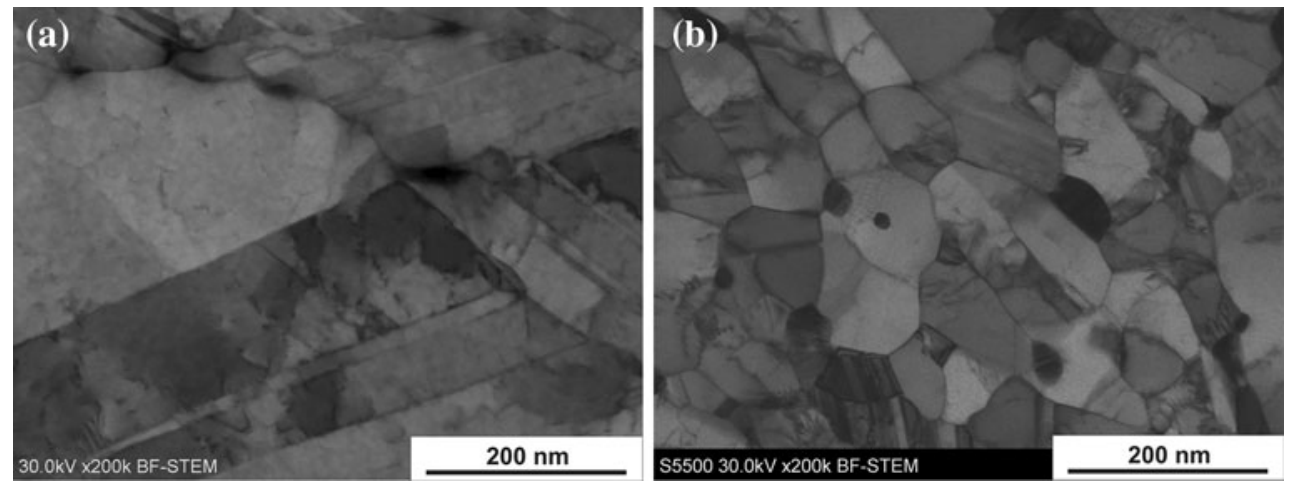

Fig. 4 Microstructures of austenitic stainless steel after annealing a the as-received and b HE-processed samples 

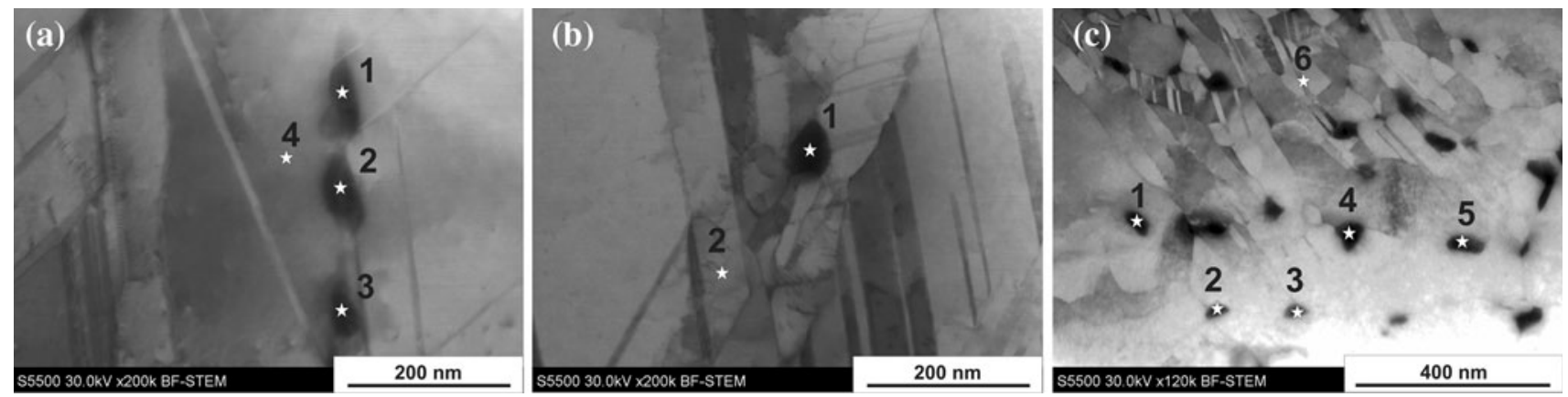

Fig. 5 Microstructures of austenitic stainless steel after annealing at $700{ }^{\circ} \mathrm{C} / \mathrm{h} \mathbf{a}, \mathbf{b}$ the as-received $\mathbf{c}$ HE-processed samples; the carbides for which chemical composition was determined are indicated

Table 3 Chemical composition of carbides (wt\%) in the as-received samples after annealing

\begin{tabular}{lllllllr}
\hline Position & Point & $\mathrm{Si}$ & $\mathrm{Cr}$ & $\mathrm{Mn}$ & $\mathrm{Fe}$ & \multicolumn{1}{l}{$\mathrm{Ni}$} & \multicolumn{1}{c}{$\mathrm{Mo}$} \\
\hline Precipitate & 1 (Fig. 5a) & 1.97 & 16.09 & 1.28 & 44.55 & 8.78 & 27.33 \\
Precipitate & 2 (Fig. 5a) & 2.95 & 13.42 & 1.00 & 29.79 & 4.49 & 48.35 \\
Precipitate & 3 (Fig. 5a) & 2.59 & 15.56 & 0.78 & 40.34 & 7.29 & 33.43 \\
Matrix & 4 (Fig. 5a) & 2.81 & 18.05 & 1.46 & 59.80 & 13.98 & 3.90 \\
Precipitate & 1 (Fig. 5b) & 1.55 & 20.32 & 0.74 & 38.08 & 4.16 & 35.15 \\
Matrix & 2 (Fig. 5b) & 2.55 & 18.17 & 1.93 & 59.38 & 14.10 & 3.87 \\
\hline
\end{tabular}

Table 4 Chemical composition of carbides (wt $\%)$ in HE-processed samples after annealing

\begin{tabular}{llllllll}
\hline Position & Point & $\mathrm{Si}$ & $\mathrm{Cr}$ & $\mathrm{Mn}$ & $\mathrm{Fe}$ & $\mathrm{Ni}$ & $\mathrm{Mo}$ \\
\hline Precipitate & 1 (Fig. 5c) & 3.02 & 11.64 & 0.30 & 27.53 & 3.35 & 54.15 \\
Precipitate & 2 (Fig. 5c) & 1.78 & 28.13 & 0.66 & 36.69 & 4.80 & 27.94 \\
Precipitate & 3 (Fig. 5c) & 2.83 & 11.47 & 0.36 & 27.09 & 3.98 & 54.27 \\
Precipitate & 4 (Fig. 5c) & 3.09 & 12.32 & 0.30 & 26.60 & 3.39 & 54.30 \\
Precipitate & 5 (Fig. 5c) & 2.77 & 12.67 & 0.40 & 27.96 & 4.58 & 51.63 \\
Matrix & 6 (Fig. 5c) & 2.12 & 18.03 & 1.34 & 59.84 & 13.59 & 5.08 \\
\hline
\end{tabular}

content of areas. The etched dimples are evenly distributed on the surface of the HE-processed samples. However, examination at high magnification revealed that the etched dimples did not form lines at grain boundaries. It is highly probable that in both samples intergranular corrosion was at the initial stage. The parameters of the size and shape of the etched dimples and their volume fraction in the asreceived and HE-processed samples after annealing for $1 \mathrm{~h}$ at $700{ }^{\circ} \mathrm{C}$ are shown in Table 5 .

The average size of etched dimples in the as-received samples was shown to be $0.96 \mu \mathrm{m}$ and was three times larger than those in the HE-processed samples. The etched dimples in the as-received samples were of submicrometer size, whereas in the HE-processed samples the etched dimples were of both nano and submicrometer size. The differences in size between the samples were well-characterised by the coefficient of variation, which is much higher in the HE-processed than in the as-received samples. On both types of sample the perimeter of the etched dimples was almost circular. In HE-processed samples the volume fraction of etched dimples on the HE material of $9.0 \%$ was much greater than the $1.9 \%$ exhibited by the as-received material.

\section{Discussion}

It was shown that the simple technique of annealing nanostructured 316LVM stainless steel for $1 \mathrm{~h}$ at $700{ }^{\circ} \mathrm{C}$ increased the elongation to fracture from 7.8 to $9.2 \%$ whilst maintaining a high UTS of $1485 \mathrm{MPa}$.

However, the results indicate that the possibility of intergranular corrosion is an important issue that must be considered when contemplating post-deformation annealing of nanostructured stainless steels. Annealing for $1 \mathrm{~h}$ at $700{ }^{\circ} \mathrm{C}$ created more nanocarbide particles in HE-processed materials that in the as-received material which consequently produced a greater volume fraction of etched dimples during the corrosion tests. This suggests that the formation of a nanostructure promotes carbide formation during annealing. However, the average equivalent diameter of the dimples was smaller in the HE-processed samples and no etched lines were visible at the grain boundaries in either condition which implies that the formation of the nanostructure does not affect the rate of corrosion.

It should be noted that sensitised steels might be more prone to other types of corrosion, such as pitting or crevice corrosion. For this reason, a novel approach should be taken to improve the ductility of nanometals, especially nanostructured steels. It has recently been proposed that an unconventional process, annealing under high pressure, achieves outstanding results [14]. Various conditions of temperature and pressure have been analysed and, to date, the best combination of ductility and strength, a ductility of 


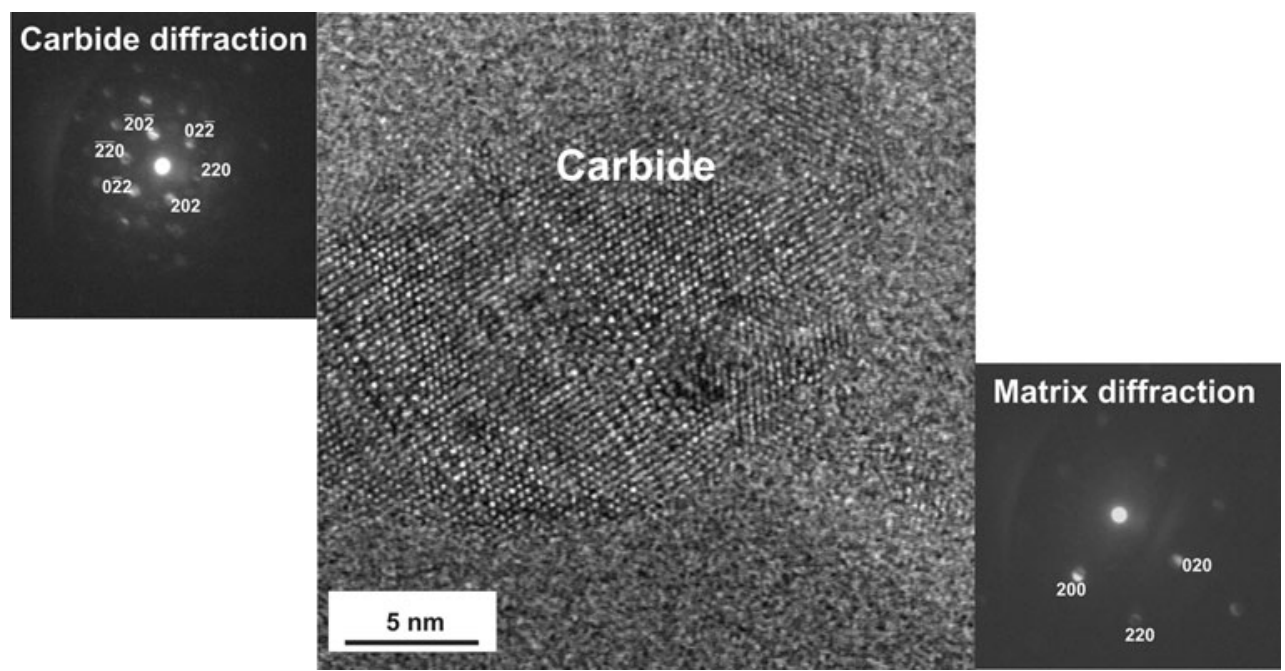

Fig. 6 High-resolution picture of a selected carbide particle and diffraction patterns from the carbide (orientation [-111]) and matrix (orientation [001])
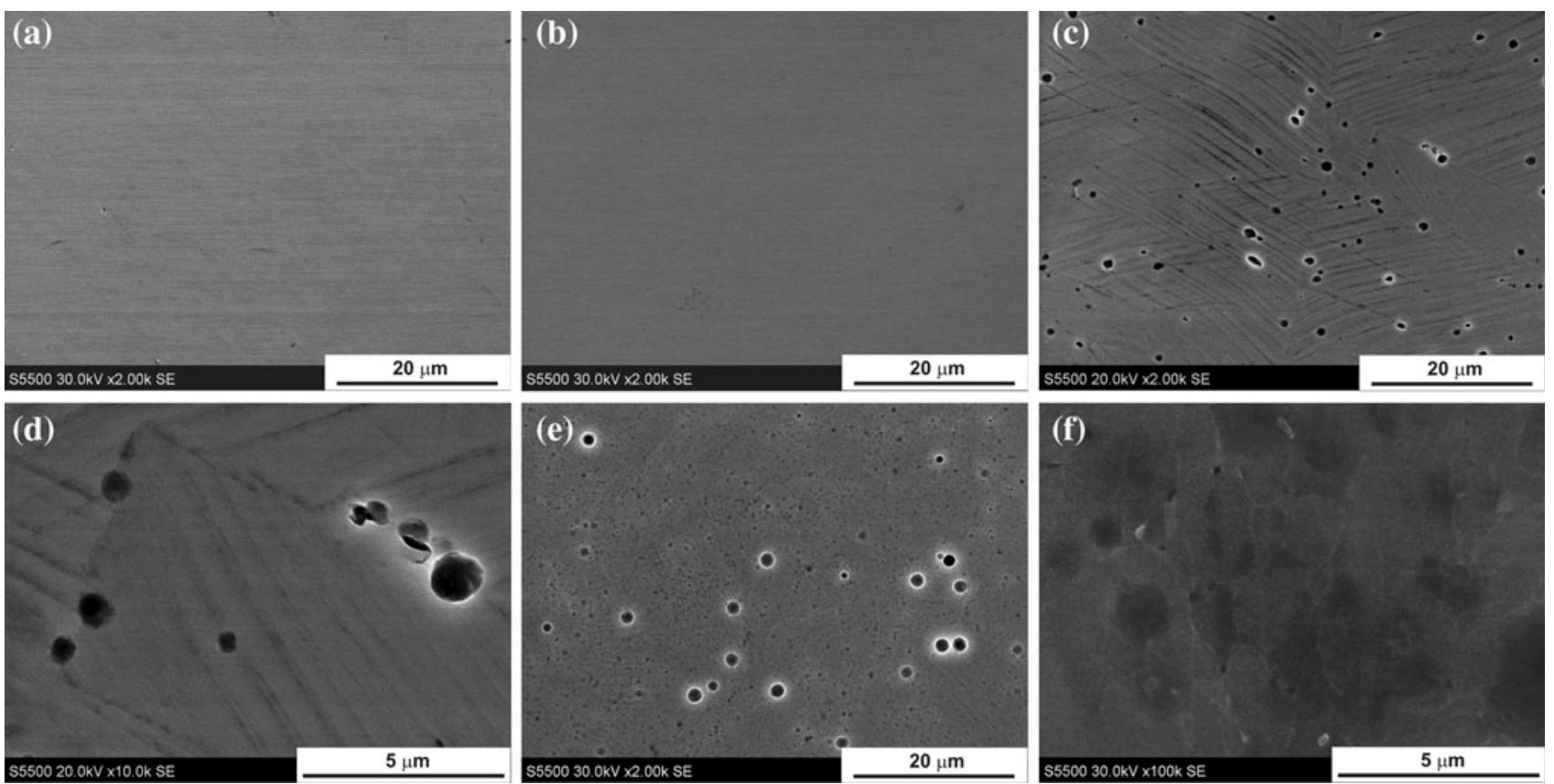

Fig. 7 Surfaces of annealed samples before corrosion tests; a as-received; b HE-processed; surfaces of annealed samples after corrosion tests; c, d as-received; e, f HE-processed

Table 5 Parameters of the size and shape of etched dimples in the annealed samples after the corrosion tests

\begin{tabular}{lllllll}
\hline Sample & \multicolumn{2}{l}{ Equivalent diameter $d_{2}$} & & & \multicolumn{2}{l}{$\begin{array}{l}\text { Volume fraction }(\%) \\
\text { of etched dimples }\end{array}$} \\
\cline { 2 - 4 } & $\mathrm{E}(\mu \mathrm{m})$ & $\mathrm{SD}(\mu \mathrm{m})$ & $\mathrm{CV}$ & & & \\
\hline As-received $+700{ }^{\circ} \mathrm{C} / 1 \mathrm{~h}$ & 0.96 & 0.31 & 0.32 & 1.21 & 1.9 \\
HE-processed $+700{ }^{\circ} \mathrm{C} / 1 \mathrm{~h}$ & 0.28 & 0.44 & 1.59 & 1.11 & 9.0 \\
\hline
\end{tabular}

$24.4 \%$ and strength of $1247 \mathrm{MPa}$, was obtained for HEprocessed 316LVM austenitic stainless steel by a heat treatment consisting annealing at $900{ }^{\circ} \mathrm{C}$ for 10 min under a pressure of $6 \mathrm{GPa}$. This treatment produced a microstructure consisting of nanograins of the average equivalent diameter of $130 \mathrm{~nm}$. It was also very significant that no carbide particles were created by this annealing process. It is possible that annealing at the high pressure 
retards the diffusion processes which lead to recovery, recrystallization, grain growth and the formation of precipitates [15-19].

\section{Conclusions}

Nanostructured austenitic steel $316 \mathrm{LVM}$ was produced by $\mathrm{HE}$ and subjected to post-deformation annealing. Tensile tests showed that after annealing for $1 \mathrm{~h}$ at $700{ }^{\circ} \mathrm{C}$ the material exhibited an enhanced ductility of $9.2 \%$ and retained a high tensile strength of $1485 \mathrm{MPa}$. However, the heat treatment sensitised the steel and promoted intergranular corrosion. The research indicates that the possibility of intergranular corrosion must be taken into account when considering post-deformation annealing of austenitic stainless steels.

Acknowledgements This work was carried out within a NANOMET Project financed by the European Funds for Regional Development (Contract No. POIG.01.03.01-00-015/08). The advice and assistance given by Prof. M. Lewandowska is much appreciated.

Open Access This article is distributed under the terms of the Creative Commons Attribution License which permits any use, distribution, and reproduction in any medium, provided the original author(s) and the source are credited.

\section{References}

1. Zhu YT, Langdon TG (2004) J Microsc 56:58
2. Lewandowska M, Kurzydlowski KJ (2008) J Mater Sci 43:7299. doi:10.1007/s10853-008-2810-z

3. Garbacz H, Lewandowska M, Pachla W, Kurzydlowski KJ (2006) J Microsc 223:272

4. Budniak J, Lewandowska M, Pachla W, Kulczyk M, Kurzydlowski KJ (2006) Solid State Phenom 114:57

5. Pisarek M, Kedzierzawski P, Plocinski T, Janik-Czachor M, Kurzydlowski KJ (2008) Mater Charact 59:1292

6. Dobatkin SV, Rybal'chenko OV, Raab GI (2007) Mater Sci Eng A $463: 41$

7. Ma E (2006) J Microsc 58:49

8. Valiev RZ, Sergueeva AV, Mukherjee AK (2003) Scripta Mater 49(7):669

9. Wang H, Shuro I, Umemoto M, Kuo H, Todaka Y (2012) Mat Sci Eng A 556:906

10. Korostlelev AB, Abramov VY, Belous VN (1996) J Nucl Mater 233-237:1361

11. Terrada M, Saiki M, Costa I, Padilha A (2006) J Nucl Mater 358:40

12. Jones R, Randle V (2010) Mater Sci Eng A 527:4275

13. Krawczynska AT, Lewandowska M, Kurzydłowski KJ (2008) Solid State Phenom 140:173

14. Krawczynska AT, Brynk T, Rosinski M, Michalski A, Gierlotka S, Grzanka E, Stelmakh S, Palosz B, Lewandowska M, Kurzydlowski KJ (2012) Improving mechanical properties of nanometals by annealing. In: Proceedings of the 33rd risoe international symposium on materials science: nanometalsstatus and perspective, 279-286

15. Tanner LE, Radcliffe SV (1962) Acta Metall Mater 10:1161

16. Syrenko AF, Klinishev GP, Khoi VT (1973) J Mater Sci 8:765. doi:10.1007/BF00553726

17. Kuhlein W, Stuwe HP (1988) Acta Metall Mater 36:3055

18. Lojkowski W (1988) J Phys-Paris 49:545

19. Sursaeva V, Protasova S, Lojkowski W, Jun J (1999) Texture Mictrostruct 32:175 